\title{
Combination therapy with a dipeptidyl peptidase-4 inhibitor and a proton pump inhibitor restores normoglycaemia in non-obese diabetic mice
}

\author{
W. L. Suarez-Pinzon • G. S. Cembrowski • \\ A. Rabinovitch
}

Received: 2 April 2009 / Accepted: 23 April 2009 /Published online: 20 May 2009

(C) Springer-Verlag 2009

Keywords Dipeptidyl peptidase- 4 - Gastrin

Glucagon-like peptide-1 NOD mice

Proton pump inhibitor . Type 1 diabetes

$\begin{array}{ll}\text { Abbreviations } \\ \text { DPP-4 } & \text { Dipeptidyl peptidase-4 } \\ \text { DPP-4i } & \text { DPP-4 inhibitor } \\ \text { GIP } & \text { Gastric inhibitory polypeptide } \\ \text { GLP-1 } & \text { Glucagon-like peptide-1 } \\ \text { NOD-scid } & \text { NOD-severe combined immunodeficient } \\ \text { PPI } & \text { Proton pump inhibitor }\end{array}$

To the Editor: Many beta cell growth factors have been identified, one of the most promising being glucagon-like peptide-1 (GLP-1), a peptide secreted from intestinal endocrine L-cells in response to nutrient ingestion. GLP-1 is rapidly cleaved and inactivated in vivo by dipeptidyl peptidase-4 (DPP-4), a ubiquitous serine protease. DPP-4 inhibitors (DPP-4i) have been shown to raise circulating levels of active GLP-1 and thus increase and maintain effective concentrations of this peptide reaching target tissues [1]. Studies in humans with type 2 diabetes have

W. L. Suarez-Pinzon · A. Rabinovitch $(\bowtie)$

Department of Medicine, University of Alberta,

1-009 HRIF-East,

Edmonton, AB, Canada T6G 2E1

e-mail: alex.rabinovitch@ualberta.ca

G. S. Cembrowski

Department of Laboratory Medicine and Pathology,

University of Alberta,

Edmonton, AB, Canada shown that DPP-4i therapy improves glucose tolerance [2]. In addition, DPP-4i treatments can preserve pancreatic beta cell mass in animal models of type 2 diabetes [3] and stimulate beta cell regeneration in streptozotocin-induced diabetic rats [4].

Regarding deficits in pancreatic beta cell mass resulting from autoimmune (type 1) diabetes, the GLP-1 analogue, exendin-4, reversed diabetes in NOD mice; however, this required additional immunosuppressive therapy [5]. Addition of the gastrointestinal peptide hormone, gastrin, to GLP-1 therapy increased pancreatic beta cell mass and restored normoglycaemia in diabetic NOD mice without the use of immunosuppressants [6]. The objective of this study was to determine whether combination therapy with a DPP$4 \mathrm{i}$ to raise endogenous levels of GLP-1, together with a proton pump inhibitor (PPI) to raise endogenous levels of gastrin, could reverse diabetes in NOD mice. Here, we report that such a combination therapy increased circulating levels of GLP-1 and gastrin in acutely diabetic NOD mice, and that pancreatic insulin content, insulin secretion and normoglycaemia were restored.

NOD female mice, age 6-8 weeks, were purchased from Taconic (Germantown, NY, USA). NOD-severe combined immunodeficient (NOD-scid) female mice were purchased from Jackson Laboratory (Bar Harbor, ME, USA). The mice were housed and fed under specific pathogen-free conditions and cared for according to the guidelines of the Canadian Council on Animal Care. Diabetes onset was diagnosed by non-fasting blood glucose $\geq 10 \mathrm{mmol} / \mathrm{l}$. Acutely diabetic NOD mice (blood glucose 10-16 mmol/l) were allocated to four groups within 4-7 days after diabetes onset and treated for 12 weeks with (1) the DPP-4i vehicle, $5 \mathrm{mg} / \mathrm{ml}$ methylcellulose in $\mathrm{H}_{2} \mathrm{O}$ given by oral gavage once daily and the PPI vehicle, PBS given by s. c. injection twice 
daily; (2) $10 \mathrm{mg} / \mathrm{kg}$ of a selective DPP-4i, 1-\{[(3-hydroxy-1adamantyl)amino]acetyl\}-2-cyano-(S)-pyrrolidine (Dalton Chemical Laboratories, Toronto, ON, Canada) given by oral gavage once daily; (3) $30 \mathrm{mg} / \mathrm{kg}$ of a PPI, pantoprazole (Nycomed, Oakville, ON, Canada) given by s. c. injection twice daily; and (4) $10 \mathrm{mg} / \mathrm{kg}$ DPP-4i and $30 \mathrm{mg} / \mathrm{kg}$ PPI.

Acutely diabetic NOD mice treated with vehicle became progressively more hyperglycaemic $(\geq 25 \mathrm{mmol} / \mathrm{l})$ and were killed within 6 weeks (Fig. 1a). Treatment with DPP-4i restored normoglycaemia in three of eight mice (38\%) (Fig. 1b) and PPI was effective in three of nine mice (33\%) (Fig. 1c). In contrast, the combination of DPP-4i and PPI restored normoglycaemia in six of eight mice $(75 \%)$ (Fig. 1d). The plasma active GLP-1 level was increased threefold by DPP-4i demonstrating protection of GLP-1 from degradation by DPP-4 enzyme; this increase in GLP-1 was not changed by additional treatment with PPI (Fig. 1e). The serum gastrin level was significantly increased by PPI demonstrating the expected elevation of gastrin production; however, addition of DPP- $4 \mathrm{i}$ treatment did not change the a

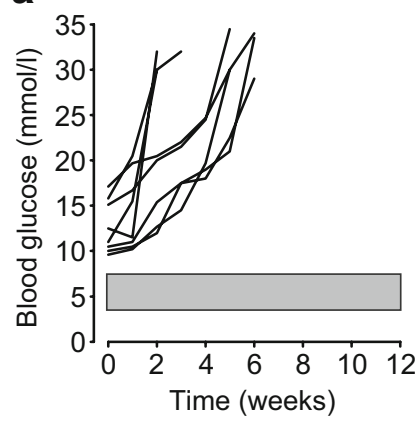

e

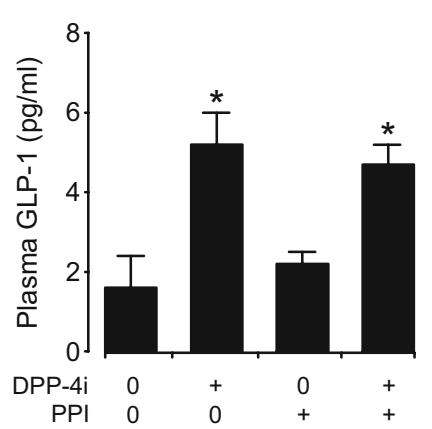

b

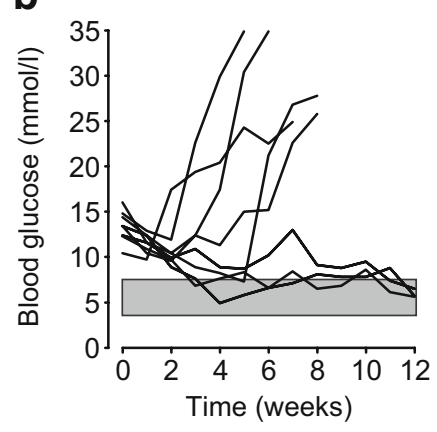

f

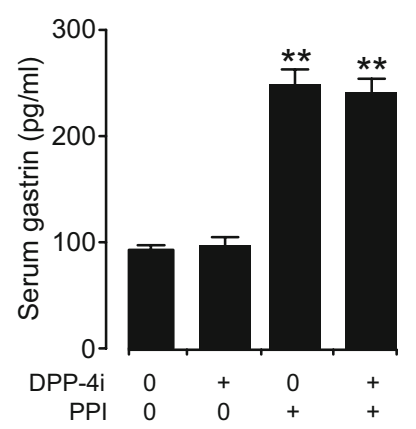

Fig. 1 Acutely diabetic NOD mice were treated with vehicle (a), $10 \mathrm{mg} / \mathrm{kg}$ DPP-4i once daily (b), $30 \mathrm{mg} / \mathrm{kg}$ PPI twice daily (c) and both $10 \mathrm{mg} / \mathrm{kg}$ DPP-4i and $30 \mathrm{mg} / \mathrm{kg}$ PPI (d) for 12 weeks. Blood glucose concentrations were measured weekly and are shown for individual mice for 12 weeks or until blood glucose was $\geq 25 \mathrm{mmol} / 1$ and the mice were killed. Normoglycaemia (blood glucose 3.5-7.0 $\mathrm{mmol} / \mathrm{l}$, shaded bar) was determined in NOD-scid mice. e Mouse active GLP-1(7-36)amide in plasma was measured by an ELISA electrochemiluminescence assay (Meso Scale Discovery, Gaithersburg, MD, USA). Serum gastrin (f) was measured using a RIA kit for the major circulating serum gastrin level achieved by PPI treatment (Fig. 1f). Treatments with DPP-4i and PPI given as single agents did not significantly increase plasma C-peptide or pancreatic insulin content compared with vehicle treatment, whereas combined DPP-4i and PPI treatments significantly increased plasma C-peptide (Fig. 1g) and pancreatic insulin content (Fig. 1h). In a follow-up study with more acutely diabetic NOD mice (blood glucose 10-16 mmol/l), we found that normoglycaemia $(3.5-7.0 \mathrm{mmol} / \mathrm{l})$ was restored in 17 of 21 mice $(81 \%)$ after 9 weeks of treatment with the combination of DPP-4i and PPI, compared with four of 14 mice $(27 \%)$ treated with DPP-4i alone $(p<0.01)$, four of 14 mice $(27 \%)$ treated with PPI alone $(p<0.01)$ and zero of 15 mice treated with vehicle $(p<0.01)$; analysis was by one-way ANOVA and Dunnett's multiple comparison tests.

DPP-4 inhibition and consequent elevation of plasma GLP-1 levels was recently reported to partially decrease diabetes incidence in NOD mice [7]. Here, we found that DPP-4 inhibition after diabetes onset in NOD mice raised plasma GLP-1 levels threefold and restored normoglycae-
C

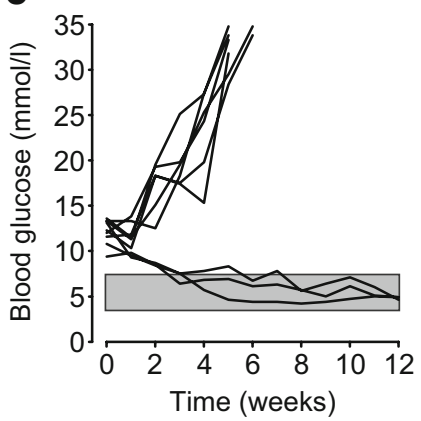

g

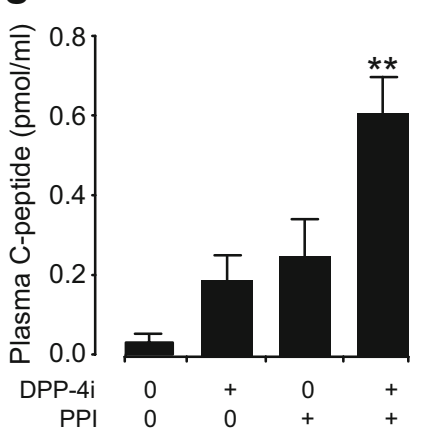

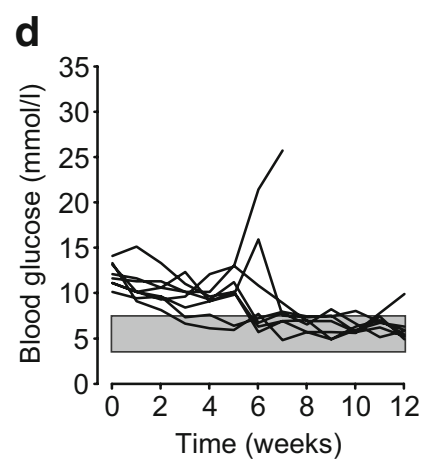

h

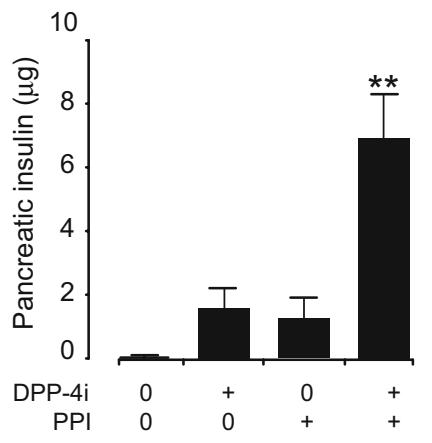

forms of human or mouse gastrin (MP Biomedicals, Orangeburg, NY, USA). C-peptide in plasma (g) was measured using a RIA kit specific for mouse C-peptide (Linco Research, St Charles, MO, USA). Pancreatic insulin content (h) was measured in ethanolic extracts of pancreas using a RIA kit for mouse insulin (Linco). e-f Mean \pm SE values are shown for all eight to nine mice in each group at the end ( $\leq 12$ weeks) of the treatments indicated. ${ }^{*} p<0.05,{ }^{* *} p<0.01$ vs vehicletreated mice (DPP-4i $0 \mathrm{mg} / \mathrm{kg}$, PPI $0 \mathrm{mg} / \mathrm{kg}$ ), analysed by one-way ANOVA and Dunnett's multiple comparison test 
mia in some of the mice; however, elevation of the serum gastrin level by concomitant PPI therapy potentiated the effects of DPP-4i treatment and normoglycaemia was restored in most of the mice; also plasma C-peptide and pancreatic insulin content were significantly increased by the combination therapy.

DPP-4 inhibition increases endogenous levels of gastric inhibitory polypeptide (GIP) and GLP-1, both of which can mediate the glucoregulatory actions of DPP-4 inhibition [8]. It is possible, therefore, that GIP, as well as GLP-1, might have contributed to the reversal of diabetes by DPP$4 \mathrm{i}$ in this study. A recent report, however, suggests that GLP-1 and not GIP has the major role in mediating DPP-4i effects on beta cell survival and function in mice [9]. The beneficial effect of PPI therapy on beta cell function and glucoregulation observed here is likely to be due to elevation of serum gastrin induced by PPI, because PPIinduced endogenous hypergastrinaemia has been reported to regenerate the endocrine pancreas and improve glucose tolerance after partial pancreatectomy in rats [10], as well as after pancreatoduodenectomy in humans [11]. The results of this study suggest that DPP-4i and PPI combination therapy may offer a promising strategy for correction of the beta cell deficit and insulin deficiency in type 1 diabetes.

Acknowledgements This work was supported by a grant from the Juvenile Diabetes Research Foundation International (17-2007-1043), and by core support from the MacLachlan Fund of the University of Alberta Hospital Foundation, and the Muttart Diabetes Research and Training Centre at the University of Alberta.

Duality of interest The authors declare that there is no duality of interest associated with this manuscript.

\section{References}

1. Kieffer TJ, McIntosh CH, Pederson RA (1995) Degradation of glucose-dependent insulinotropic polypeptide and truncated glucagon-like peptide 1 in vitro and in vivo by dipeptidyl peptidase IV. Endocrinology 136:3585-3596

2. Drucker DJ, Nauck MA (2006) The incretin system: glucagon-like peptide-1 receptor agonists and dipeptidyl peptidase-4 inhibitors in type 2 diabetes. Lancet 368:1696-1705

3. Mu J, Woods J, Zhou Y-P et al (2006) Chronic inhibition of dipeptidyl peptidase- 4 with a sitagliptin analog preserves pancreatic $\beta$-cell mass and function in a rodent model of type 2 diabetes. Diabetes 55:1695-1704

4. Pospisilik JA, Martin J, Doty T et al (2003) Dipeptidyl peptidase IV inhibitor treatment stimulates beta cell survival and islet neogenesis in streptozotocin induced diabetic rats. Diabetes 52:741-750

5. Ogawa N, List JF, Habener JF, Maki T (2004) Cure of overt diabetes in NOD mice by transient treatment with anti-lymphocyte serum and exendin-4. Diabetes 53:1700-1705

6. Suarez-Pinzon WL, Power RF, Yan Y, Wasserfall C, Atkinson M, Rabinovitch A (2008) Combination therapy with glucagon-like peptide-1 and gastrin restores normoglycemia in diabetic NOD mice. Diabetes 57:3281-3288

7. Kim S-J, Nian C, Doudet DJ, McIntosh CHS (2009) Dipeptidyl peptidase IV inhibition with MK0431 improves islet graft survival in diabetic NOD mice partially via $\mathrm{T}$ cell modulation. Diabetes 58:641-651

8. Hansotia T, Baggio LL, Delmeire D et al (2004) Double incretin receptor knockout (DIRKO) mice reveal an essential role for the enteroinsular axis in transducing the glucoregulatory actions of DPP-IV inhibitors. Diabetes 53:1326-1335

9. Maida A, Seino Y, Drucker DJ (2008) Differential importance of GIP vs GLP-1 receptor signaling vs DPP-4 inhibition for beta cell survival and function in mice. Diabetologia 51(Suppl 1):S363

10. Xu G, Sumi S, Koike M, Tanigawa K, Nio Y, Tamura K (1996) Role of endogenous hypergastrinemia in regenerating endocrine pancreas after partial pancreatectomy. Dig Dis Sci 41:2433-2439

11. Jang J-Y, Kim S-W, Han J-K et al (2003) Randomized prospective trial of the effect of induced hypergastrinemia on the prevention of pancreatic atrophy after pancreatoduodenectomy in humans. Ann Surg 237:522-529 